\title{
Midline interhemispheric variant of holoprosencephaly
}

INSERM

\section{Source}

INSERM. (1999). Orphanet: an online rare disease and orphan drug data base. Midline interhemispheric variant of holoprosencephaly. ORPHA:93926

Midline interhemispheric variant of holoprosencephaly $(\mathrm{MIH})$ or syntelencephaly is a form of holoprosencephaly (HPE; see this term) characterized by non-separation of the posterior frontal and parietal lobes, normally-formed callosal genu and splenium, absence of the callosal body, normally-separated hypothalamus and lentiform nucleus, and frequent heterotopic gray matter. 